\title{
Effects of eight weeks of resistance training on the risk factors of metabolic syndrome in overweight /obese women - "A Pilot Study"
}

Ramires Alsamir Tibana ${ }^{1,2^{*}}$, James Navalta ${ }^{3}$, Martim Bottaro ${ }^{4}$, Denis Vieira ${ }^{1}$, Vitor Tajra', Alessandro de Oliveira Silva ${ }^{1}$, Darlan Lopes de Farias', Guilherme Borges Pereira' ${ }^{1}$, Jéssica Cardoso de Souza', Sandor Balsamo ${ }^{2,6}$,

Claudia Regina Cavaglieri ${ }^{5}$ and Jonato Prestes ${ }^{1 *}$

\begin{abstract}
Background: The purpose of the present study was to examine the effects of eight weeks of resistance training (RT) on anthropometric, cardiovascular and biochemical risk factors of metabolic syndrome (MetS), and neuromuscular variables on overweight/obese women.
\end{abstract}

Methods: Fourteen middle-aged (33.9 \pm 8.6 years) overweight/obese women (body mass index - BMl $29.6 \pm 4.1 \mathrm{~kg} / \mathrm{m}^{2}$ ) underwent 24 sessions ( 3 times/week) of a whole body RT program with 3 sets of 8-12 repetitions maximum (RM). The following variables were evaluated: maximum strength on chest press and frontal lat pull-down; isometric hand-grip strength; biceps brachii (BB) and rectus femoris (RF) muscle thickness, body mass; BMl; body adiposity index (BAl); waist, hip and neck circumferences; visceral fat volume; blood glucose; glycated hemoglobin (HbA1c); insulin; HDL-C and triglycerides.

Results: There was an increase of chest press (from $52.9 \pm 9.7$ to $59.8 \pm 7.7 \mathrm{~kg} ; \mathrm{P}=0.02$ ) and front lat pull-down (from $51.5 \pm 7.5$ to $57.6 \pm 9.2 \mathrm{~kg} ; P=0.01)$ muscle strength, isometric handgrip $(P=0.02)$ and RF muscle thickness (from $42.2 \pm 8.5$ to $45.1 \pm 7.3 \mathrm{~mm} ; \mathrm{P}=0.02$ ) after the 8 week RT program. There were no statistically significant alterations on plasma glucose, $\mathrm{HbA1c}$, insulin, triglycerides, $\mathrm{HDL}-\mathrm{C}$, anthropometric indexes and BB muscle thickness $(p>0.05)$

Conclusions: A RT program without caloric restriction promotes an increase on muscle thickness and strength, with no effects on risk factors of MetS in overweight/obese women.

Keywords: Resistance training, Obesity, Overweight, Metabolic syndrome

\section{Introduction}

The prevalence of Metabolic Syndrome (MetS) has been increasing worldwide, in parallel with the increasing prevalence of obesity. MetS is characterized by the grouping of several cardiovascular risk factors such as: abdominal obesity, hypertension, insulin resistance, glucose intolerance/type 2 diabetes, and dyslipidemia [1]. Furthermore, various epidemiologic studies have shown strong associations between these risk factors and

\footnotetext{
* Correspondence: ramiires@hotmail.com; jonatop@gmail.com

${ }^{1}$ Graduate Program on Physical Education, Catholic University of Brasilia, Q.S.

07 Lote 01 - Bloco G, 71966-700, Brasilia, Brazil

${ }^{2}$ Department of Physical Education, Euro-American University Center (UNIEURO), Brasilia, Brazil

Full list of author information is available at the end of the article
}

the development of other chronic diseases problems such as gastrointestinal cancer [2], diabetes [3], cardiovascular disease (CVD) [4], or even premature mortality $[5,6]$. Thus, the development of strategies to prevent and treat MetS, overweight and obesity are of great importance.

Sedentary behavior which includes activities such as lying down, sitting, watching television, using the computer, and other forms of screen based entertainment are positively associated with an increased risk of type 2 diabetes [7,8], cancer [9], MetS [10], and all-cause and CVD mortality $[7,8]$. Therefore, lifestyle modifications [11] and exercise have been consistently recommended for the treatment and prevention of hypertension and metabolic diseases. Aerobic exercises such as walking

\section{Ciomed Central}


and bicycling have been widely used to prevent the development of metabolic and cardiovascular risk factors, MetS, type 2 diabetes, CVD, and premature mortality [12].

Nevertheless, the inclusion of resistance training (RT) as an integral part of an exercise program which also includes aerobic or combined exercise has been endorsed by the American Heart Association [13], the American College of Sports Medicine [14] and the American Diabetes Association [15]. Recent studies have suggested that lower levels of muscular strength are associated with the prevalence of MetS [16,17], obesity [18], hypertension [19] and premature mortality [20]. Moreover, RT for persons with MetS induces no additional systemic elevation of pro-inflammatory cytokines [21] and is effective in reducing clinical and $24 \mathrm{~h}$ blood pressure in middle-aged overweight/obese women [22]. However, Stensvold et al., [23] found minimal effects of RT on risk factors of MetS. The conflicting data reinforce the necessity of more studies investigating the effects of RT on the risk factors of MetS.

The purpose of the present study was to examine the effects of eight weeks of RT on anthropometric, cardiovascular and biochemical risk factors of MetS, and neuromuscular variables in overweight/obese women. The initial hypothesis was that chronic RT without dietary restriction would improve neuromuscular variables and decrease some risk factors of MetS, such as blood pressure and waist circumference.

\section{Methods}

\section{Subjects}

Initially, 20 women from the local community volunteered to participate from posters and lectures about the study. However, only 14 completed the study, with three volunteers excluded due to caloric restriction and three excluded from the statistical analysis because they missed more than $25 \%$ of the training sessions (Figure 1). Individuals completed a thorough physical examination, including a medical history, resting and exercise electrocardiogram [24], blood pressure assessment, anthropometric, and orthopaedic evaluation prior to participation in the experimental protocols. As inclusion criteria, the only participants included were those aged between $18-40 \mathrm{y}$, classified as overweight $(\mathrm{N}=9)$ or obese $(\mathrm{N}=5)$ by BMI measurement according to the World Health Organization (WHO): overweight BMI $=25.0-29.9 \mathrm{~kg} \cdot \mathrm{m}^{2}$ and obese $>30.0 \mathrm{~kg} \cdot \mathrm{m}^{2}$, and those without consistent RT for the past six months before the study period. Women with physical disabilities, under caloric restriction, diagnosis of diabetes, cardiovascular diseases, hypertension (systolic blood pressure $>140 \mathrm{mmHg}$ and diastolic blood pressure $>90 \mathrm{mmHg}$ ) [25], musculoskeletal disease, recent use of medication and smoking or drug/alcohol abuse were excluded from the trial. Sedentary state was defined

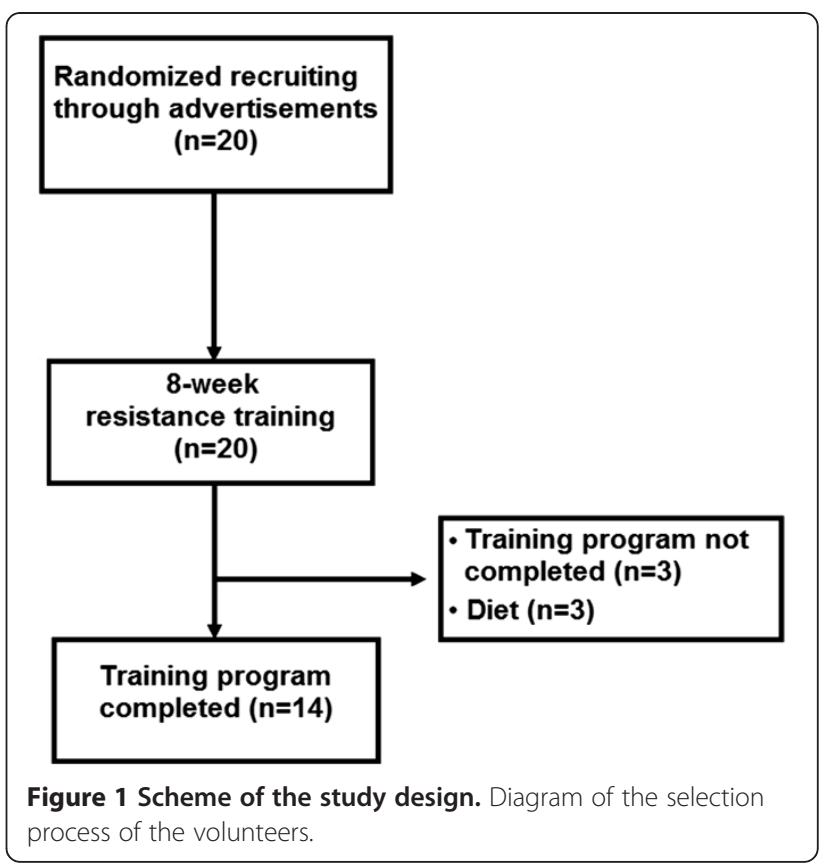

by the International physical activity questionnaire (IPAQ). All participants signed an informed consent document and the study was approved by the Catholic University of Brasilia Research Ethics Committee for Human Use (protocol \#279/2010).

\section{Study design}

The present study was designed to investigate the effects of eight weeks of RT on muscle thickness and strength, anthropometric, biochemical and cardiovascular risk factors of MetS in overweight/obese women. All testing and training sessions were conducted between 08:00-09:00 pm. Subjects were advised to maintain their normal daily eating habits throughout the study (this was guaranteed by a dietary recall follow-up).

Prior to physical evaluation, participants reported to the laboratory between 08:00-10:00 am following an overnight fast, for blood sampling from the antecubital vein for subsequent analysis of biochemical variables. Anthropometric variables, isometric handgrip strength, muscle thickness by ultrasound and thorough physical examination were determined. Volunteers completed two weeks of familiarization prior to testing (3 sessions/ week, with one exercise for each main muscle group which were the same exercises used during RT), where they were advised regarding the execution of proper technique. After the familiarization period, one-repetition maximum (1-RM) test and re-test were performed on the chest press and front lat pull-down on two nonconsecutive days with 48-72 hours between tests. The RT protocol began three days after 1-RM testing and was performed on three non-consecutive days of the week, 
comprising three sets of $8-12$ repetition maximum (RM) of twelve exercises, and 1-minute rest intervals between sets and exercises.

\section{Maximal strength testing}

After 2 weeks of adaptation to the exercises and 3-5 days after the last training session, 1-RM tests were performed on 2 different days separated by a minimum of $48 \mathrm{~h}$. All tests were performed with 10 min rest intervals between each exercise. The order was as follows: chest press and front lat pull-down (JOHNSON, USA). The protocol consisted of a light warm-up of $10 \mathrm{~min}$ of treadmill running followed by 8 repetitions at $50 \%$ of estimated 1-RM (according to the participants' capacity verified in the 2 weeks of adaptation). After a 1-min rest, subjects performed 3 repetitions at $70 \%$ of the estimated 1-RM. Following 3 minutes of rest, participants completed 3-5 attempts interspersed with 3-to-5 min rest intervals, with progressively heavier weights $(\sim 5 \%)$ until the 1-RM was determined. The range of motion and exercise technique were standardized according to the descriptions of Brown and Weir [26].

\section{Isometric handgrip strength}

Isometric handgrip strength was determined by a manual mechanical dynamometer (Takei, T.K.K Grip strength dynamometer $0-100 \mathrm{~kg}$, Japan), according to the recommendations of Heyward [27]. Volunteers stood still with both arms extended and the forearm positioned in a neutral rotation. The handgrip width of the dynamometer was individually adjusted for each participant, according to hand size allowing the stem next to the body to be positioned on the second phalanges: index, medial and ring fingers. Three attempts were allowed interspersed with 1 min rest intervals. The best measure was used and relative isometric strength was determined as follows:

Relative strength $=$ Absolute strength $(\mathrm{kg}) /$ Body mass $(\mathrm{kg})$

\section{Muscle thickness}

Muscle thickness of the rectus femoris (RF) and biceps brachii $(\mathrm{BB})$ were tested before and after the eight-week RT period. All tests were conducted at the same time of day, and participants were instructed to hydrate normally $24 \mathrm{~h}$ before the tests. Measures were taken 3-5 days after the last training session to prevent any residual effects (i.e. swelling) that could interfere with muscle thickness [28]. Participants were instructed to avoid any other type of exercise or intense activity. Muscle thickness was measured using B-Mode ultrasound (Philips-VMI, Ultra Vision Flip, model BF). A water-soluble transmission gel was applied to the measurement site and a $7.5-\mathrm{MHz}$ ultrasound probe was placed perpendicular to the tissue interface while not depressing the skin. Muscle thickness of the use only RF and $\mathrm{BB}$ muscle from the dominant limb were measured according to the recommendations of Abe et al., [29]. Once the technician was satisfied with the quality of the image produced, the image on the monitor was frozen. With the image frozen, a cursor was enabled in order to measure muscle thickness, which was taken as the distance from the subcutaneous adipose tissue-muscle interface to muscle-bone interface [29]. A trained technician performed all the analysis.

\section{Total muscle mass}

Total muscle mass was estimated according to the equation proposed by Lee et al., [30]:

$$
\begin{aligned}
\text { Skeletal muscle mass }(\mathrm{kg})= & \mathrm{Ht}_{\mathrm{m}}(0.244 \times \mathrm{BM}) \\
& +\left(7.8 \times \mathrm{Ht}_{\mathrm{m}}\right)+(6.6 \times \text { gender }) \\
& -(0.098 \times \text { age })+(\text { ethnicity }-3.3)
\end{aligned}
$$

Where: $\mathrm{Ht}_{\mathrm{m}}$, height $(\mathrm{m}) ; \mathrm{BM}$, body mass $(\mathrm{kg})$; gender: male $=1, \quad$ female $=0$; ethnicity: Asian $=1.4$, AfricanAmerican $=1.2$, White $=0$.

\section{Anthropometric variables}

Height and weight were measured for the calculation of the body mass index (BMI). All circumferences were obtained using non elastic tape, and measurements were obtained in triplicate and averaged to obtain the circumference score. Neck circumference was obtained with the subject sitting with the head in the Frankfort horizontal plane position. Briefly, a measuring tape was applied around the neck inferior to the laryngeal prominence and perpendicular to the long axis of the neck, while the minimal circumference was measured and recorded to the nearest $0.1 \mathrm{~cm}$ [31]. Waist circumference was measured at the midpoint between the lower rib margin and the (Yang et al., 2010). Body adiposity index (BAI) was determined by the following formula: $(\mathrm{BAI}=[($ hip circumference $) /(($ height $) 1.5)-18)][32]$.

\section{Volume of visceral fat}

The volume of visceral fat (VVF) was estimated using the predictive equation proposed by Petribu et al., [33] that uses as independent variables the waist-to-height ratio (WHtR) and fasting glucose (FG), as follows:

$$
\begin{aligned}
\mathrm{VVF}= & -130.941+(198.673 \times \mathrm{WHtR}) \\
& +(1.185 \times \mathrm{FG})
\end{aligned}
$$

This equation was developed from a multiple regression analysis by adopting the ultrasonography as a reference standard. 


\section{Blood pressure measurement}

Systolic (SBP), diastolic (DBP) and mean blood pressure (MBP) were measured before the initiation of the training program and four days after the RT was finished with an oscillometric device (Microlife 3 AC1-1, Widnau, Switzerland) according to the recommendations of the VI Brazilian Guidelines on Hypertension [25]. The cuff size was adapted to the circumference of the arm of each participant according to the manufacture's recommendations. SBP and DBP values were used to determine MBP according to the following equation:

$$
\mathrm{MBP}=\mathrm{DBP}+[(\mathrm{SBP}-\mathrm{DBP}) / 3]
$$

Heart rate (HR) was measured by a HR monitor (Polar ${ }^{\circledR}$ S810i, Polar Electo Oy, Kempele, Finland). All blood pressure measures were assessed in triplicate (measurements separated by $1 \mathrm{~min}$ ) with the mean value used for analysis.

\section{Biochemical parameters}

Participants reported to the laboratory between 08:0010:00 am, after an overnight fast, for blood withdrawal from the antecubital vein. Plasmatic triglycerides, HDLcholesterol and glucose levels were measured by enzymatic CHOP-POD, homogeneous HDL-cholesterol and Hexokinase methods, respectively. Plasma insulin concentration was measured using a Roche Diagnostics Elecsys 2010 system (Roche Diagnostics, Indianapolis, IN, USA) by the sandwich principle. Glycated hemoglobin (HbA1c) was measured by turbidimetric immunoinhibition on an LX20 analyzer (Beckman Instruments, Brea, CA, USA).

\section{Resistance training program}

Subjects completed two weeks of familiarization prior to the RT program. In the familiarization weeks individuals:they were advised regarding proper RT technique and completed 3 sessions/week, with one exercise of each main muscle group consisting of 3 sets of 10-12 submaximal repetitions. After the familiarization period subjects initiated The RT program consisting of 3 sessions/week during eight weeks. RT machines were from JOHNSON (Landmark Drive, Cottage Grove, USA). All training sessions were carefully supervised by three experienced professionals (ratio of supervision 1:2 1 professor for 2 participants). Participants were required to complete at least $85 \%$ of the exercise sessions. No major complications or cardiac events occurred during the study period. Figure 2 shows the exercise order that was strictly followed. The RT was divided into A (Monday) and B (Tuesday) and whole body (Friday) regiments. Abdominal crunches (three sets of 15 repetitions in all sessions) were included. For all listed exercises, three sets with 8-12 RM were performed, with a one-minute rest interval between

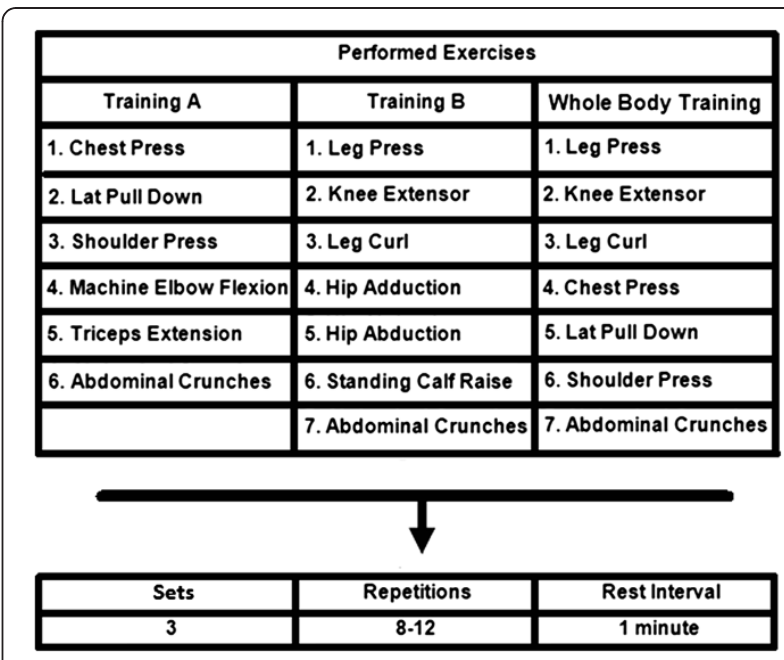

Figure 2 Division of the RT sessions throughout the study. For all exercises, 3 sets of $8-12$ repetitions maximum were performed with 1-minute rest interval between each set and exercise.

each set and exercise. Training loads were monitored each session according to the increase in muscle capacity of the participants. The mean duration to complete one repetition was 3-4 s (both concentric and eccentric phases of the movement) and training sessions lasted $\approx 40-50 \mathrm{~min}$. The number of repetitions and the loads used for each exercise session were recorded. The loads were updated when necessary to keep the number of repetitions within the same range of $\mathrm{RM}$ and to provide a progressive overload. Additionally, correct breathing patterns were instructed to avoid Valsalva maneuver.

\section{Statistical analysis}

Data are reported as means \pm standard deviation (SD). The normal distribution of the data was checked using The Shapiro-Wilk normality test and a homoscedasticity test (Mauchly). The pre and post-intervention variables were compared by using paired Student's $t$-test and Wilcoxon test for the nonparametric data. In addition, the correlation between delta (post-pre) of muscle strength and thickness with delta (post-pre) of anthropometric and biochemical variables were checked by means of Spearman correlation. The magnitude of differences was verified by the effect size (ES) of Cohen with threshold values of 0.2 (small), 0.6 (moderate), 1.2 (large), and 2.0 (very large) considered. Significance level was set at $\mathrm{P}<0.05$. Considering the variable muscle strength, the estimated sample size required would be of seven individuals for a Power of $80 \%$. All data were analyzed using the Statistical Package for Social Sciences (SPSS, v.19, Chicago, IL).

\section{Results}

Subjects' general characteristics are presented in Table 1. There were no statistically significant alterations after 
Table 1 Anthropometric and hemodynamic characteristics of the subjects $(n=14)$ before and after eight weeks of resistance training

\begin{tabular}{|c|c|c|c|c|c|}
\hline Variables & Pre & Post & $\Delta$ & $\mathbf{P}$ & ES \\
\hline Age (y) & $33.9 \pm 8.6$ & - & - & - & - \\
\hline Body mass (kg) & $75.5 \pm 12.9$ & $76.4 \pm 14.1$ & 0.96 & 0.14 & 0.07 \\
\hline Height (m) & $1.59 \pm 0.08$ & - & - & - & - \\
\hline $\mathrm{BMI}\left(\mathrm{kg} \cdot \mathrm{m}^{2}\right)$ & $29.6 \pm 4.1$ & $29.9 \pm 4.2$ & 0.36 & 0.13 & 0.09 \\
\hline WC (cm) & $88.4 \pm 10.1$ & $89.1 \pm 8.9$ & 0.77 & 0.45 & 0.08 \\
\hline $\mathrm{HC}(\mathrm{cm})$ & $107.5 \pm 8.8$ & $108.0 \pm 8.9$ & 0.52 & 0.45 & 0.06 \\
\hline $\mathrm{NC}(\mathrm{cm})$ & $34.9 \pm 1.9$ & $35.2 \pm 1.7$ & 0.30 & 0.35 & 0.15 \\
\hline BAI (\%) & $27.0 \pm 3.9$ & $27.3 \pm 3.6$ & 0.21 & 0.45 & 0.06 \\
\hline WHpR & $0.82 \pm 0.07$ & $0.83 \pm 0.06$ & 0.01 & 0.63 & 0.05 \\
\hline $\mathrm{WHtR}$ & $0.55 \pm 0.06$ & $0.56 \pm 0.05$ & 0.01 & 0.45 & 0.08 \\
\hline$W F\left(\mathrm{~cm}^{2}\right)$ & $88.4 \pm 22.1$ & $90.0 \pm 25.1$ & 1.65 & 0.61 & 0.07 \\
\hline SBP $(\mathrm{mmHg})$ & $127.9 \pm 15.1$ & $123.2 \pm 9.6$ & -4.7 & 0.19 & 0.31 \\
\hline $\mathrm{DBP}(\mathrm{mmHg})$ & $83.7 \pm 10.1$ & $81.6 \pm 8.7$ & -2.1 & 0.15 & 0.20 \\
\hline $\mathrm{MBP}(\mathrm{mmHg})$ & $98.4 \pm 10.9$ & $95.5 \pm 8.7$ & -2.9 & 0.11 & 0.27 \\
\hline
\end{tabular}

BMI, body mass index (kg.m2); WC, waist circumference (cm), HC, hip circumference $(\mathrm{cm})$; $\mathrm{NC}$, neck circumference $(\mathrm{cm}), \mathrm{BAl}$, body adiposity index (\%); WHpR, waist to hip ratio; WHtR, waist to height ratio; VVF, volume of visceral fat $\left(\mathrm{cm}^{2}\right)$; SBP, systolic blood pressure $(\mathrm{mmHg})$; DBP, diastolic blood pressure $(\mathrm{mmHg}) ; \mathrm{MBP}$, mean blood pressure $(\mathrm{mmHg}) ; \mathrm{ES}$, effect size.

eight weeks of RT on the anthropometric and blood pressure variables $(\mathrm{P}>0.05)$. Additionally, ES values were between 0.05 and 0.31 , indicating small magnitudes.

Table 2 presents data from biochemical variables. Again, there were no statistically significant modifications after the RT program on blood glucose $(\mathrm{P}=0.38)$, glycated hemoglobin $(\mathrm{P}=0.63)$, insulin $(\mathrm{P}=0.38)$, triglycerides $(\mathrm{P}=0.38)$, HDL-C $(\mathrm{P}=0.69)$ and triglycerides/HDL ratio $(\mathrm{P}=0.74)$. Magnitudes of the ES were small, between 0.08 and 0.23 .

Neuromuscular variables are presented in Table 3. There was a significant increase for chest press $(\mathrm{P}=0.02)$, front lat pull-down $(\mathrm{P}=0.01)$, right handgrip and left handgrip $(\mathrm{P}=0.02)$ strength after the RT program. There was an increase in the RF muscle thickness $(P=0.02)$. Values of ES were of small to moderate magnitude from 0.27 to 0.70 . However, there were no

Table 2 Biochemical variables of the subjects $(n=14)$ before and after eight weeks of resistance training

\begin{tabular}{lccccc}
\hline Variables & Pre & Post & $\boldsymbol{\Delta}$ & P & ES \\
\hline Glucose $(\mathrm{mg} \cdot \mathrm{dL})$ & $89.7 \pm 19.4$ & $94.2 \pm 19.1$ & 4.5 & 0.38 & 0.23 \\
HbAlc $(\%)$ & $5.29 \pm 0.49$ & $5.32 \pm 0.54$ & 0.04 & 0.63 & 0.08 \\
Insulin $(\mu \mathrm{Ul} \cdot \mathrm{mL}) \dagger$ & $7.32 \pm 7.55$ & $11.7 \pm 8.5$ & 4.4 & 0.15 & - \\
Triglycerides $(\mathrm{mg} \cdot \mathrm{dL}) \dagger$ & $95.0 \pm 70.7$ & $85.0 \pm 41.9$ & -10.0 & 0.13 & - \\
HDL $(\mathrm{mg} \cdot \mathrm{dL})$ & $47.4 \pm 19.8$ & $49.8 \pm 15.1$ & 2.45 & 0.69 & 0.12 \\
TG/HDL ratio† & $2.16 \pm 1.32$ & $2.25 \pm 1.34$ & 0.08 & 0.74 & - \\
\hline
\end{tabular}

TValues expressed as median; HbAlc, glycated hemoglobin; ES, effect size. $H D L$, high-density lipoprotein; $T G$, triglycerides.
Table 3 Neuromuscular variables of the subjects $(n=14)$ before and after eight weeks of resistance training

\begin{tabular}{lccccc}
\hline Variables & Pre & Post & $\boldsymbol{\Delta}$ & $\mathbf{P}$ & ES \\
\hline Chest press (kg) & $52.9 \pm 9.7$ & $59.8 \pm 7.7^{*}$ & 6.8 & 0.02 & 0.71 \\
Relative strength & $0.71 \pm 0.09$ & $0.79 \pm 0.15^{*}$ & 0.08 & 0.03 & 0.88 \\
Front lat pull-down (kg) & $51.5 \pm 7.5$ & $57.6 \pm 9.2^{*}$ & 6.1 & 0.01 & 0.81 \\
Relative strength & $0.69 \pm 0.11$ & $0.75 \pm 0.13^{*}$ & 0.06 & 0.01 & 0.56 \\
Right handgrip (kg) & $30.1 \pm 6.4$ & $31.6 \pm 5.5^{*}$ & 1.7 & 0.02 & 0.27 \\
Relative strength & $0.40 \pm 0.09$ & $0.42 \pm 0.08$ & 0.02 & 0.08 & 0.23 \\
Left handgrip (kg) & $28.2 \pm 5.6$ & $30.5 \pm 4.6^{*}$ & 2.2 & 0.02 & 0.40 \\
Relative strength & $0.38 \pm 0.07$ & $0.40 \pm 0.06$ & 0.03 & 0.07 & 0.35 \\
Biceps MT (mm) & $26.1 \pm 5.4$ & $24.8 \pm 2.7$ & -1.3 & 0.26 & 0.24 \\
Rectus femoris MT (mm) & $42.2 \pm 8.5$ & $45.1 \pm 7.3^{*}$ & 2.8 & 0.02 & 0.33 \\
Total muscle mass (kg) & $25.6 \pm 3.8$ & $25.8 \pm 4.2$ & 0.2 & 0.15 & 0.06 \\
*Statistically significant different as compared with Pre, P $\leq 0.05, \mathrm{MT}$, muscle \\
thickness (mm); ES, effect size.
\end{tabular}

statistically significant differences on total muscle mass $(\mathrm{P}=0.15)$ and $\mathrm{BB}$ muscle thickness $(\mathrm{P}=0.26)$.

The correlations among the variables of the study are summarized on Table 4 . There were positive correlations of body mass and total muscle mass with relative muscle strength of front lat pull-down $(\mathrm{p}<0.05)$, and inverse correlations of insulin with chest press relative muscle strength $(\mathrm{p}<0.05)$, VVF with relative muscle strength of right handgrip $(\mathrm{p}<0.05)$, triglycerides and TG/HDL ratio with BB muscle thickness $(\mathrm{p}<0.05)$.

\section{Discussion}

The aim of the present study was to analyze the effects of eight weeks of RT on anthropometric, cardiovascular and biochemical risk factors of MetS, and neuromuscular variables on overweight/obese women. The results of

Table 4 Correlation of delta (post-pre) of muscle strength and thickness with delta (post-pre) of anthropometric and biochemical variables

\begin{tabular}{lcccc}
\hline Variables & $\begin{array}{c}\text { Chess press } \\
\text { (relative) }\end{array}$ & $\begin{array}{c}\text { Front lat } \\
\text { pull-down } \\
\text { (relative) }\end{array}$ & $\begin{array}{c}\text { Right hand grip } \\
\text { (relative) }\end{array}$ & $\begin{array}{c}\text { Biceps MT } \\
\text { (mm) }\end{array}$ \\
\hline $\begin{array}{l}\text { Body } \\
\text { mass }(\mathrm{kg})\end{array}$ & $\mathrm{NS}$ & $\mathbf{0 . 5 3 ^ { * }}$ & $\mathrm{NS}$ & $\mathrm{NS}$ \\
$\mathrm{TMM}(\mathrm{kg})$ & $\mathrm{NS}$ & $\mathbf{0 . 5 3 ^ { * }}$ & $\mathrm{NS}$ & $\mathrm{NS}$ \\
$\mathrm{WF}\left(\mathrm{cm}^{2}\right)$ & $\mathrm{NS}$ & $\mathrm{NS}$ & $-0.60^{*}$ & $\mathrm{NS}$ \\
Insulin & $-0.60^{*}$ & $\mathrm{NS}$ & $\mathrm{NS}$ & $\mathrm{NS}$ \\
$(\mu \mathrm{Ul} \cdot \mathrm{mL})$ & & & & \\
$\mathrm{TG}$ & $\mathrm{NS}$ & $\mathrm{NS}$ & $\mathrm{NS}$ & $-0.63^{*}$ \\
$(\mathrm{mg} \cdot \mathrm{dL})$ & & & & \\
$\mathrm{TG} / \mathrm{HDL}$ & $\mathrm{NS}$ & $\mathrm{NS}$ & $\mathrm{NS}$ & $-0.57^{*}$ \\
ratio & & & & \\
\hline
\end{tabular}

*Statistically significant $(P \leq 0.05), M T$, muscle thickness; TMM, total muscle mass; VVF, volume of visceral fat; TG, Triglycerides; NS, non-significant. 
the present study revealed that chronic RT induced an increase of RF muscle thickness and muscle strength, with no effects on anthropometric, cardiovascular and biochemical risk factors of MetS in overweight/obese women. Additionally, there was a correlation between the chronic increase of relative muscle strength with a decrease of triglycerides, TG/HDL ratio, insulin and VVF.

RT is recommended by the American Heart Association [13], the American College of Sports Medicine [14] and the American Diabetes Association [15] as an effective tool to prevent and treat metabolic diseases. These recommendations are based on evidence showing that RT promotes increased muscle mass, glucose transporter (GLUT-4), protein kinase B and glycogen synthase in obese and diabetic individuals [34]. However, fully understanding of the mechanisms responsible for the decrease in blood pressure and dyslipidemia remain to be determined.

On the other hand, results of the present study revealed that despite the increase of RF muscle thickness and muscle strength, no modifications were observed for blood glucose, HDL-C, insulin and glycated hemoglobin. Similarly, meta-analytic data showed that isolated exercise programs without caloric restriction induced limited improvements on cardiovascular risk factors. Shaw et al., [35] evaluated 43 studies including 3476 participants and found that exercise without caloric restriction control is associated with a lower decrease of body mass, blood pressure and blood glucose as compared with exercise associated with dietary restriction. Orozco et al., [36] compared the effects of isolated diet and diet + aerobic and RT. Results showed that diabetes risk was lower in the combined group. Additionally, individuals submitted to exercise training + diet presented a decrease of blood pressure and anthropometric indexes of obesity, which was not observed for the group of isolated exercise.

Another relevant difference of the present study as compared with other interventions with overweight/ obese individuals was that no aerobic exercise was allowed, which may explain the limited results found on risk factors for MetS. This is reinforced by the results from Libardi et al., [37], in which overweight individuals completed 16 weeks of aerobic + RT and exhibited increased aerobic capacity and improved lipid profile. In this sense, Ismail et al., [38], found that aerobic exercise training induced a decrease in visceral fat, while RT induced no modification on this parameter. Another study from Potteiger et al., [39] compared the effects of aerobic exercise at $65-80 \%$ of maximum heart rate and RT at 5-10RM with caloric restriction on the cardiovascular risk factor of MetS. The authors reported that aerobic training induced a decrease of MetS $\mathrm{z}$ score after six months, while no results were found for RT.
Sigal et al., [40] investigated the effects of aerobic, RT and combined (aerobic + RT) training on cardiovascular risk factors in type 2 diabetic individuals. Similar to the results of the present study, there was no alteration on blood pressure, HDL-C, LDL-C and triglycerides after isolated RT. Furthermore, only aerobic and combined training induced significant modifications on body composition. Finally, after 22 weeks of RT associated with dietetic reeducation, there was a decrease of glycated hemoglobin, while combined training induced a superior decrease on glycated hemoglobin compared to only aerobic or RT.

Regarding the neuromuscular variables evaluated in the present study, muscle strength and RF muscle thickness increased after eight weeks of RT. Previous studies revealed that even after brief RT, muscle strength [41] and muscle thickness increase $[42,43]$. Although muscle thickness determined by ultrasound technique may not differentiate hydration status, muscle, connective tissue and intramuscular fat, this technology is considered a reliable method to measure muscle thickness [44]. A possible explanation for the increase of RF muscle thickness was that more exercises were completed for the lower limb, while only one specific for biceps brachii was included (arm curl). The increase of muscle strength would be expected as initial strength gains (1-8 weeks) due to strength training are primarily neural adaptations [45]. In addition, the increase of muscle strength is of greater importance to the maintenance of functional capacity as compared to other physical variables [46], which may prevent several degenerative process associated with overweight and obesity.

The present study has some limitations that should be considered, such as the limited time of the intervention (only eight weeks), the reduced number of participants and lack of more accurate measures to evaluate body composition. Another limitation was the lack of a control group, although it has been speculated that a control group is not always necessary, particularly considering that the health of the individuals could be compromised as a result of not participating in RT. Additionally, results from a control group would probably reveal no positive effect on anthropometric, biochemical and cardiovascular risk factor of MetS, as has been reported in other studies $[23,40,47]$. Finally, the non significant variation of the biochemical data, such as glucose and insulin values can be, at least in part, attributed to the lack of dietetic control. Probably, an interdisciplinary approach would induce more positive results on biochemical and anthropometric variables, as previously shown in obese adolescents $[48,49]$.

In summary, eight weeks of RT without caloric restriction had no effects on biochemical, anthropometric and cardiovascular risk factors of MetS in overweight/obese 
women. However, RT induces important improvement of muscle strength and RF muscle thickness in this population. The increase of muscle strength and lower limb muscle thickness are important outcomes to improve and/or maintain functional capacity during daily living activities, which may prevent chronic degenerative process associated with sedentary lifestyle. It can be hypothesized that longer interventions and the association of RT with aerobic exercise, in addition to the caloric restriction would induce superior results on risk factors of MetS.

\section{Competing interests}

This research received no specific grant from any funding agency in the public, commercial, or not-for-profit sectors. The authors declare no competing interest.

\section{Authors' contributions}

RAT, AdeOS, CRC, GBP and JP were responsible for concept and design, statistical expertise, data analysis and interpretation, helped write the manuscript. RAT, JN, MB and JP were responsible for data analysis and interpretation and helped write the manuscript. DV, JN, VT, DLdeF, SB and JCdeS were significant manuscript reviewers/revisers and were responsible for data analysis and interpretation. All authors have read and approved the manuscript for publication.

\section{Author details}

${ }^{1}$ Graduate Program on Physical Education, Catholic University of Brasilia, Q.S. 07 Lote 01 - Bloco G, 71966-700, Brasilia, Brazil. ²Department of Physical Education, Euro-American University Center (UNIEURO), Brasilia, Brazil. ${ }^{3}$ Kinesiology and Nutrition Sciences, University of Nevada, Las Vegas, USA. ${ }^{4}$ College of Physical Education, University of Brasilia, Brasilia, Brazil. ${ }^{5}$ School of Physical Education, State University of Campinas, Campinas, Brazil. ${ }^{6}$ Graduate Program in Medical Sciences of the University of Brasilia, School of Medicine - UnB, Brasilia, DF, Brazil.

Received: 1 February 2013 Accepted: 24 February 2013

Published: 28 February 2013

\section{References}

1. Cornier MA, Dabelea D, Hernandez TL, Lindstrom RC, Steig AJ, Stob NR, Van Pelt RE, Wang H, Eckel RH: The metabolic syndrome. Endocr Rev 2008, 29(7):777-822

2. Matthews CE, Sui X, LaMonte MJ, Adams SA, Hébert JR, Blair SN: Metabolic syndrome and risk of death from cancers of the digestive system. Metabolism 2010, 59(8):1231-1239.

3. Wilson PW, D'Agostino RB, Parise H, Sullivan L, Meigs JB: Metabolic syndrome as a precursor of cardiovascular disease and type 2 diabetes mellitus. Circulation 2005, 112(20):3066-3072.

4. Isomaa B, Almgren P, Tuomi T, Forsén B, Lahti K, Nissén M, Taskinen MR, Groop L: Cardiovascular morbidity and mortality associated with the metabolic syndrome. Diabetes Care 2001, 24(4):683-689.

5. Katzmarzyk PT, Church TS, Janssen I, Ross R, Blair SN: Metabolic syndrome, obesity, and mortality: impact of cardiorespiratory fitness. Diabetes Care 2005, 28(2):391-397.

6. Lakka HM, Laaksonen DE, Lakka TA, Niskanen LK, Kumpusalo E, Tuomilehto J, Salonen JT: The metabolic syndrome and total and cardiovascular disease mortality in middle-aged men. JAMA 2002, 288(21):2709-2716.

7. Proper Kl, Singh AS, van Mechelen W, Chinapaw MJM: Sedentary behaviors and health outcomes among adults. A systematic review of prospective studies. Am J Prev Med 2011, 40(2):174-182.

8. van Uffelen JG, Wong J, Chau JY, van der Ploeg HP, Riphagen I, Gilson ND, Burton NW, Healy GN, Thorp AA, Clark BK, Gardiner PA, Dunstan DW, Bauman A, Owen N, Brown WJ: Occupational sitting and health risks a systematic review. Am J Prev Med 2010, 39(4):379-388.

9. Lynch BM, Sedentary Behavior and Cancer: A systematic review of the literature and proposed biological mechanisms. Cancer Epidemiol Biomarkers Prev 2010, 19(11):2691-2709.
10. Edwardson CL, Gorely T, Davies MJ, Gray LJ, Khunti K, Wilmot EG, Yates T, Biddle SJ: Association of sedentary behaviour with metabolic syndrome: a meta-analysis. PLoS One 2012, 7(4):e34916.

11. Mecca MS, Moreto F, Burini FH, Dalanesi RC, McLellan KC, Burini RC: Ten-week lifestyle changing program reduces several indicators for metabolic syndrome in overweight adults. Diabetol Metab Syndr 2012, 19(1):1.

12. Nocon M, Hiemann T, Muller-Riemenschneider F, Thalau F, Roll S, Willich SN: Association of physical activity with all-cause and cardiovascular mortality: a systematic review and meta-analysis. Eur J Cardiovasc Prev Rehabil 2008, 15(3):239-246.

13. Pollock ML, Franklin BA, Balady GJ, Chaitman BL, Fleg JL, Fletcher B, Limacher M, Piña IL, Stein RA, Williams M, Bazzarre T: AHA science advisory. Resistance exercise in individuals with and without cardiovascular disease: benefits, rationale, safety, and prescription. An advisory from the Committee on Exercise, Rehabilitation, and Prevention, Council on Clinical Cardiology, American Heart Association; Position paper endorsed by the American College of Sports Medicine. Circulation 2000, 101(7):828-833.

14. Donnelly JE, Blair SN, Jakicic JM, Manore MM, Rankin JW, Smith BK, and American College of Sports Medicine: American college of sports medicine position stand. Appropriate physical activity intervention strategies for weight loss and prevention of weight regain for adults. Med Sci Sports Exerc 2009, 41(2):459-471.

15. Sigal RJ, Kenny GP, Wasserman DH, Castaneda-Sceppa C: Physical activity/ exercise and type 2 diabetes. Diabetes Care 2004, 27(10):2518-2539.

16. Jurca R, Lamonte MJ, Church TS, Earnest CP, Fitzgerald SJ, Barlow CE, Jordan AN, Kampert JB, Blair SN: Associations of muscle strength and fitness with metabolic syndrome in men. Med Sci Sports Exerc 2004, 36(8):1301-1307.

17. Mota J, Vale S, Martins C, Gaya A, Moreira C, Santos R, Ribeiro JC: Influence of muscle fitness test performance on metabolic risk factors among adolescent girls. Diabetol Metab Syndr 2010, 23(2):42.

18. Jackson AW, Lee DC, Sui X, Morrow JR Jr, Church TS, Maslow AL, Blair SN: Muscular strength is inversely related to prevalence and incidence of obesity in adult men. Obesity 2010, 18(10):1988-1995.

19. Maslow AL, Sui X, Colabianchi N, Hussey J, Blair SN: Muscular strength and incident hypertension in normotensive and prehypertensive men. Med Sci Sports Exerc 2010, 42(2):288-295.

20. Newman AB, Kupelian V, Visser M, Simonsick EM, Goodpaster BH, Kritchevsky SB: Strength, but not muscle mass, is associated with mortality in the health, aging and body composition study cohort. J Gerontol A Biol Sci Med Sci 2006, 61(1):72-77.

21. Pereira GB, Tibana RA, Navalta J, Sousa NMF, Córdova C, Souza VC, Nobrega OT, Prestes J, Perez SEA: Acute effects of resistance training on cytokines and osteoprotegerin in women with metabolic syndrome. Clin Physiol Funct Imaging 2013, 33(2):122-130.

22. Tibana RA, Pereira GB, Bottaro M, Navalta J, Prestes J: Acute effects of resistance exercise on clinical and 24-hour ambulatory blood pressure in middle-aged overweight and obese women. Int J Sports Med 2012. in press.

23. Stensvold D, Tjønna AE, Skaug EA, Aspenes S, Stølen T, Wisløff U, Slørdahl $S A$ : Strength training versus aerobic interval training to modify risk factors of metabolic syndrome. J Appl Physiol 2010, 108(4):804-810.

24. Tavel ME: Stress testing in cardiac evaluation: current concepts with emphasis on the ECG. Chest 2001, 119(3):907-925.

25. Sociedade Brasileira de Cardiologia, Sociedade Brasileira de Hipertensão, Sociedade Brasileira de Nefrologia: VI Brazilian Guidelines on Hypertension. Arq Bras Cardiol 2010, 95(1):1-51.

26. Brown LE, Weir JP: Procedures recommendation I: accurate assessment of muscular strength and power. J Exerc Physiol 2001, 4(1):1-21.

27. Heyward VH: Assessing muscular fitness. In Advanced fitness assessment. Edited by Heyward VH. Champaign, IL: Human Kinetics; 2010:129-154.

28. Chilibeck PD, Stride D, Farthing JP, Burke DG: Effect of creatine ingestion after exercise on muscle thickness in males and females. Med Sci Sports Exerc 2004, 36(10):1781-1788.

29. Abe T, DeHoyos DV, Pollock ML, Garzarella L: Time course for strength and muscle thickness changes following upper and lower body resistance training in men and women. Eur J Appl Physiol 2000, 81(3):174-180.

30. Lee RC, Wang Z, Heo M, Ross R, Janssen I, Heymsfield SB: Total-body skeletal muscle mass: development and cross-validation of anthropometric prediction models. Am J Clin Nutr 2000, 72(3):796-803. 
31. Yang GR, Yuan SY, Fu HJ, Wan G, Zhu LX, Bu XL, Zhang JD, Du XP, Li YL, Ji Y, Gu XN, Li Y, Beijing Community Diabetes Study Group: Neck circumference positively related with central obesity, overweight, and metabolic syndrome in Chinese subjects with type 2 diabetes: Beijing Community Diabetes Study. Diabetes Care 2010, 33(11):2465-2467.

32. Bergman RN, Stefanovski D, Buchanan TA, Sumner AE, Reynolds JC, Sebring NG, Xiang AH, Watanabe RM: A better index of body adiposity. Obesity 2011, 19(5):1083-1089.

33. Petribu MMV, Guimarães FJSP, Cabral PC, Santos EMC, Diniz AS, Arruda IKG: Development and validation of prediction equations for visceral fat in young women. Rev bras cineantropom desempenho hum 2012, 14(3):333-342.

34. Ciccolo JT, Carr LJ, Krupel KL, Longval JL: The role of resistance training in the prevention and treatment of chronic disease. Am J Lifestyle Med 2010, 4(4):293-308.

35. Shaw K, Gennat H, O'Rourke P, Del Mar C: Exercise for overweight or obesity. Cochrane Database Syst Rev 2006, 8(4):CD003817.

36. Orozco LJ, Buchleitner AM, Gimenez-Perez G, Roqué I, Figuls M, Richter B, Mauricio D: Exercise or exercise and diet for preventing type 2 diabetes mellitus. Cochrane Database Syst Rev 2008, 16(3):CD003054.

37. Libardi CA, De Souza GV, Cavaglieri CR, Madruga VA, Chacon-Mikahil MP: Effect of resistance, endurance, and concurrent training on TNF- $a$, IL-6, and CRP. Med Sci Sports Exerc 2012, 44(1):50-56.

38. Ismail I, Keating SE, Baker MK, Johnson NA: A systematic review and meta-analysis of the effect of aerobic vs. resistance exercise training on visceral fat. Obes Rev 2012, 13(1):68-91.

39. Potteiger JA, Claytor RP, Hulver MW, Hughes MR, Carper MJ, Richmond S, Thyfault JP: Resistance exercise and aerobic exercise when paired with dietary energy restriction both reduce the clinical components of metabolic syndrome in previously physically inactive males. Eur J Appl Physiol 2012, 112(6):2035-2044.

40. Sigal RJ, Kenny GP, Boulé NG, Wells GA, Prud'homme D, Fortier M, Reid RD, Tulloch $H$, Coyle D, Phillips $P$, Jennings A, Jaffey J: Effects of aerobic training, resistance training, or both on glycemic control in type 2 diabetes: a randomized trial. Ann Intern Med 2007, 147(6):357-369.

41. Phillips MD, Patrizi RM, Cheek DJ, Wooten JS, Barbee JJ, Mitchell JB: Resistance training reduces subclinical inflammation in obese, postmenopausal women. Med Sci Sports Exerc 2012, 44(11):2099-2110.

42. Nogueira W, Gentil P, Mello SN, Oliveira RJ, Bezerra AJ, Bottaro M: Effects of power training on muscle thickness of older men. Int I Sports Med 2009, 30(3):200-204.

43. Bottaro M, Veloso J, Wagner D, Gentil P: Resistance training for strength and muscle thickness: effect of number of sets and muscle group trained. Sci sports 2010, 26(5):259-264.

44. Bemben MG: Use of diagnostic ultrasound for assessing muscle size J Strength Cond Res 2002, 16(1):103-108

45. Deschenes MR, Kraemer WJ: Performance and physiologic adaptations to resistance training. Am J Phys Med Rehabil 2002, 81(11):S3-S16.

46. Bean JF, Kiely DK, Herman S, Leveille SG, Mizer K, Frontera WR, Fielding RA: A comparison of leg power and leg strength within the InCHIANTI study: which influences mobility more? J Gerontol A Biol Sci Med Sci 2003, 58(8):728-733.

47. Nybo L, Sundstrup E, Jakobsen MD, Mohr M, Hornstrup T, Simonsen L, Bülow J, Randers MB, Nielsen JJ, Aagaard P, Krustrup P: High-intensity training versus traditional exercise interventions for promoting health. Med Sci Sports Exerc 2010, 42(10):1951-1958.

48. Lira FS, Rosa JC, Pimentel GD, Santos RV, Carnier J, Sanches PL, de Piano A, de Souza CT, Tock L, Tufik S, de Mello MT, Seelaender M, Oller do Nascimento CM, Oyama LM, Dâmaso AR: Long-term interdisciplinary therapy reduces endotoxin level and insulin resistance in obese adolescents. Nutr J 2012, 18(11):74.

49. Lira FS, Rosa JC, Dos Santos RV, Venancio DP, Carnier J, Sanches Pde L, do Nascimento CM, de Piano A, Tock L, Tufik S, de Mello MT, Dâmaso AR, Oyama LM: Visceral fat decreased by long-term interdisciplinary lifestyle therapy correlated positively with interleukin- 6 and tumor necrosis factor- $\alpha$ and negatively with adiponectin levels in obese adolescents. Metabolism 2011, 60(3):359-365.

doi:10.1186/1758-5996-5-11

Cite this article as: Tibana et al:: Effects of eight weeks of resistance training on the risk factors of metabolic syndrome in overweight /obese women - "A Pilot Study". Diabetology \& Metabolic Syndrome 2013 5:11.

\section{Submit your next manuscript to BioMed Central and take full advantage of:}

- Convenient online submission

- Thorough peer review

- No space constraints or color figure charges

- Immediate publication on acceptance

- Inclusion in PubMed, CAS, Scopus and Google Scholar

- Research which is freely available for redistribution 